\title{
Formulating Method to Improve Web Quality: Integrating Fuzzy Logic, Web Quality, and Refined Kano
}

\author{
Ridho Rahatesa $^{1}$, Yati Rohayati ${ }^{2}$, Galang Aji Pangestu ${ }^{3}$ \\ ${ }^{1,2}$ School of Industrial and System Engineering, Telkom University, Bandung, Indonesia \\ ${ }^{3}$ School of Communication and Business, Telkom University, Bandung, Indonesia \\ e-mail: ridhorahatesa@student.telkomuniversity.ac.id
}

\begin{abstract}
Disruption of technology requires businesses to perform digital transformation in its product marketing, one of which includes owning an e-commerce website. By having an e-commerce website, businesses get detailed consumer behavior patterns from their visits. This pattern of behavior can be utilized for future business process development. The importance of the existence of this e-commerce website requires businesses to be able to provide the best service when consumers access the website. In this research, the appropriate methods are formulated for businesses to improve the quality of their e-commerce services. In previous studies, Web Quality and Refined Kano methods are often used to improve the quality of e-commerce services. Although the two methods are often integrated to find more accurate recommendations, the recommendations produced are still subjective and have a high level of ambiguity. To reduce the level of subjectivity and ambiguity, it is necessary to integrate fuzzy logic into Web Quality and Refined Kano. The integration of fuzzy, Web Quality, and Refined Kano methods is expected to provide the most accurate and objective recommendations for businesses to improve the quality of their e-commerce services.
\end{abstract}

Keywords—Fuzzy Logic, Web Quality, Refined Kano, e-Commerce Services.

\section{INTRODUCTION}

$\mathrm{I}^{\mathrm{N}}$ N 2019, the local industry in Indonesia experienced growth in contribution to Indonesia's GDP of Rp.1,211 trillion from Rp.1,105 trillion in 2018 [1]. This is influenced by the digital disruption of Indonesian internet users which have touched 145 million users and $63.5 \%$ of them have transacted online. Thus, this requires companies to use the internet such as marketplaces and sales websites as a medium for marketing and selling their products to certain market segments [2].

Today, the sales and marketing mediums do not only use conventional shops but also use marketplaces, sales websites and social media. Although the marketplace has many advantages for consumers, the complete database of consumers is not directly owned by the company. So, companies cannot see and fully control the database for in-depth analysis of consumer behavior [3]. Sales websites, that are owned directly by the company, can give a distinctive brand impression to potential customers and understand consumer behavior in-depth when customers accessing the sales website. With a sales website, companies can get a more detailed consumer database for future product marketing needs.

To improve sales website services, especially for sites that want to attract more users, a lot of previous research has integrated Web Quality and Refined Kano Model to find the true customer needs by potential customers. Web Quality is a method used to find the attributes of needs that are categorized as strong and weak based on the Customer Importance Value [4]. Strong and weak attributes help the company to identify the most important parts of a service to be developed first. Meanwhile, the Refined Kano Model is used to find out more detailed interest categories for potential customers [5]. The category is determined by the prospective customer's answers from functional and dysfunctional statements.

However, the integration of the two methods still give subjective results and has a high level of ambiguity. This is because both methods process the single answer data of potential customers directly from the questionnaire that uses indicators of linguistic variables. Thus, the prospective customer's answer is only represented by one feeling.

To reduce the level of subjectivity and ambiguity for improving the sales website services, we need to integrate fuzzy logic into Web Quality and Refined Kano Model. According to the fuzzy logic theory, a person's feelings cannot be represented by one feeling because each person has a vague and divergent view. Integration of Fuzzy, Web Quality and Refined Kano are expected to provide the most accurate and objective recommendations for businesses to improve their company's website sales services.

\section{METHOD}

This research aims to create the right method in developing sales website services by integrating fuzzy logic method, Web Quality, and the Refined Kano Model. This research was carried out by exploring and in-depth understanding of previous studies related to the object of research and integrated research methods. The exploratory approach is carried out by comparing previous studies and finding relationships between methods so that common ground for these methods is found. Previous research exploration can identify the right stages to be used in the integration process so it can produce the most appropriate 


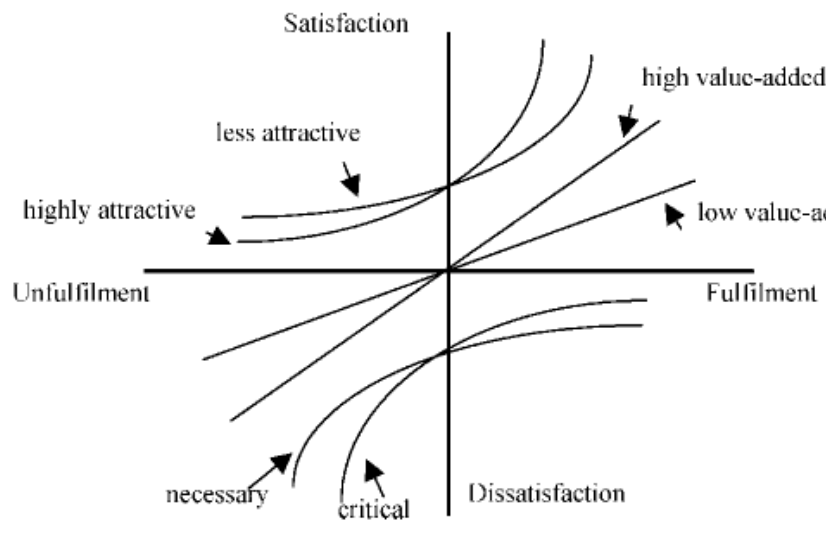

Figure 1. Refined Kano Model Atributes.

and objective research output to be used in improving the quality of sales website services. The results of the research using the integration of these methods are true customer needs (TCN). TCN is an improved design that is used in implementing quality improvement services on sales websites.

This study uses the data processing services improvement sales website of "ARTCH", a local fashion company from Bandung, with a similar method as a case example in explaining the process of using the integration of the methods in this study.

\section{RESULTS AND DISCUSSION}

\section{A. Review of Web Quality}

Web Quality Model is an approach to defining and measuring the quality of a website by analyzing user needs so the website can have diverse content with an established and flexible function. [4]. This model is a further development of the Service Quality Model. Web Quality model is more specific and relevant to the dimensions that exist on the website, while the Service Quality Model has dimensions that are still too common if used for research for the website services. In the following explanation, we can see the dimensions of the Web Quality Model used in the case example based on previous studies.

1) Quality Characteristics [6]

The website has a display that is easily understood and operated by users without spending a large effort. In addition, the website also has an established functionality as an attraction to fulfill services that are actually needed by users.

\section{2) Information Quality [7]}

The ability of a website to provide users with clear, complete and relevant information and content such as images, videos, and text. And has a secure information system if the user wants to make a product purchase transaction through the website.

3) Responsiveness [8]

Availability of web sites to assist and provide functionality in interacting with users. Having the ability to work fast, short response times and website capabilities when complex transactions occur.

4) Emphaty [8]
The ability of the website to pay attention to the needs and desires of users. It can be to navigate and personalize the ability to prioritize user desires.

\section{5) Community Support [9]}

The ability of the website to increase user satisfaction by providing communication facilities between the company and users, and between users. The website also has a service that allows users to collaborate with each other.

The concept of web site changes as technology changes. The first generation of websites is known as Web of Documents (Web 1.0) which is have functions to disseminate general information and show existence to internet users. Web of People (Web 2.0) is the second generation of websites that already allows users to interact, exchange information and communicate both ways through social media. Web of Data (Web 3.0) which is currently developing is a third-generation website that can personalize the needs and desires of users, be able to integrate data and do deep learning [10].

This change has resulted in some concepts in the Web Quality dimension being not fully relevant for developing the quality of web site design today. Changes in current technology trends are followed by changes in the design of websites that are specified as User Experience (UX) Design [11]. UX Design is considered more relevant in the development of current web sites and case example of this research.

User Experience is the level of positive or negative emotions that can be experienced by users in certain contexts during and after product use and which motivates for further use [12]. While, UX in the design perspective pay more attention to product appearance and experience quality [13]

After combined the results of adjusting the case example of this study to previous research and the results of the critique of the Web Quality Model, then there are six dimensions used in this study, such as (1) Quality Characteristics [6]; (2) Information Quality [7]; (3) Responsiveness [8]; (4) Emphaty [8]; (5) Community Support [9]; (6) User Experience [14].

\section{B. Review of Refined Kano}

The Kano model was pioneered by a Japanese professor Noriaki Kano with some of his colleagues. This model is a very useful tool for understanding customer needs and the impact of those needs [15]. The Kano model allows us to further analyze customer needs by knowing the ability of a customer's needs to achieve customer satisfaction and be a determinant of the needs of a product or service.

The Kano model is very useful for developing and improving the quality of a product or service. However, there are a number of conditions where the Kano Model cannot meet the important attributes of customer needs. The Kano Model that was developed by considering the interests of customers on certain quality attributes to identify needs is called the Refined Kano Model [16].

As can be seen in Figure 1, there are eight categories of quality attributes in the Refined Kano Model. Here's an explanation of the category of attributes found in the Refined Kano Model [16]: 
IPTEK Proceedings Series No. (1) (2020), ISSN (2354-6026)

International Conference on Business and Engineering Management 2020 (IConBEM 2020)

Table 1.

Kano Model Evaluation Table

\begin{tabular}{|c|c|c|c|c|c|c|}
\hline \multirow{2}{*}{\multicolumn{2}{|c|}{ Customer Needs }} & \multicolumn{5}{|c|}{ Dysfunctional } \\
\hline & & Like & Must-be & Neutral & Live With & Dislike \\
\hline \multirow{5}{*}{ 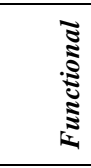 } & Like & $\mathrm{Q}$ & $\mathrm{A}$ & $\mathrm{A}$ & $\mathrm{A}$ & $\mathrm{O}$ \\
\hline & Must-be & $\mathrm{R}$ & I & I & $\mathrm{I}$ & M \\
\hline & Neutral & $\mathrm{R}$ & I & I & $\mathrm{I}$ & M \\
\hline & Live With & $\mathrm{R}$ & I & $\mathrm{I}$ & $\mathrm{I}$ & M \\
\hline & Dislike & $\mathrm{R}$ & $\mathrm{R}$ & $\mathrm{R}$ & $\mathrm{R}$ & $\mathrm{Q}$ \\
\hline \multirow{2}{*}{\multicolumn{2}{|c|}{$\begin{array}{l}\mathrm{A}=\text { Attractive } \\
\mathrm{O}=\text { One-dimensional }\end{array}$}} & & Must-be & \multirow{2}{*}{\multicolumn{2}{|c|}{$\begin{array}{l}\mathrm{R}=\text { Reverse } \\
\mathrm{Q}=\text { Questionable }\end{array}$}} & \\
\hline & & & different & & & \\
\hline
\end{tabular}

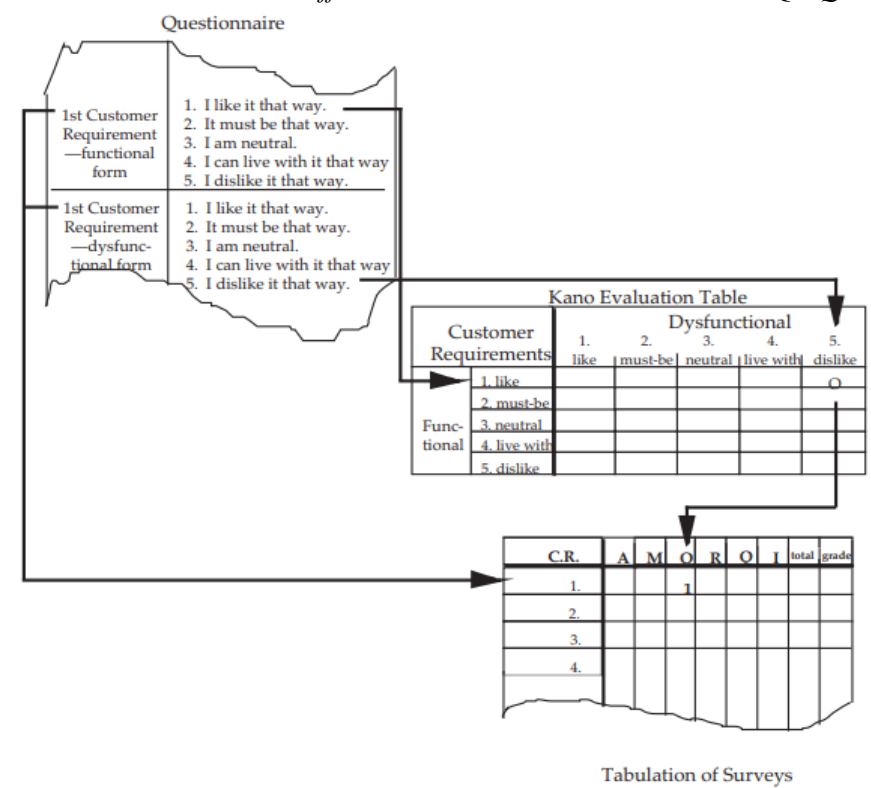

Figure 2. Model Kano Tabulation.

1) Highly attractive quality

This category is classified as a high category in the attractive Kano Model category. This category is great for companies to get potential customers to use products or services. Implementing this category will increase customer satisfaction. But if not, it will not cause dissatisfaction with the customer.

2) Less attactive quality

This category is relatively low in the attractive Kano Model category. This category can be considered for use because of the small value of interest that is gained from customers. Implementing this category will increase customer satisfaction. But if not, it will not cause dissatisfaction with the customer.

3) High value-added quality

This category is classified as a high category in the onedimensional Kano Model category. This category contributes very high to the level of customer satisfaction. Implementing this category will increase customer satisfaction. But if not, it will cause dissatisfaction with the customer.

4) Low value-added quality

This category is classified as a low category in the onedimensional Kano Model category. This category makes a small or limited contribution to the level of customer satisfaction. Implementing this category will increase customer satisfaction. But if not, it will cause dissatisfaction with the customer.

\section{5) Critical quality}

This category is classified as having a high level of importance in the Must-be Kano Model category. This category is very important for customers. Business actors must be able to meet the needs of customers. Implementing this category will only affect the neutral level of customer satisfaction. But if not, it will cause dissatisfaction with the customer.

6) Necessary quality

This category is classified as a low level of importance in the Must-be Kano Model category. This category requires products to reach the level needed to maintain customer satisfaction.

\section{7) Potential quality}

This category is a high category in the Indifferent Kano Model category. This category will gradually become attractive, so it needs to be considered to be the right strategy in attracting customers in the future. Implementing this category will not affect the level of customer satisfaction.

\section{8) Care-free quality}

This category is classified as a low category in the Indifferent Kano Model category. So, it can be ignored with certain considerations. Implementing this category will not affect the level of customer satisfaction.

The Kano Model evaluation table above is a way to classify customer needs attributes so they can categorize all the needs attributes according to the Kano category. There are six Kano 
IPTEK Proceedings Series No. (1) (2020), ISSN (2354-6026)

International Conference on Business and Engineering Management 2020 (IConBEM 2020)

February $1^{\text {st }}$ 2020, Institut Teknologi Sepuluh Nopember, Surabaya, Indonesia

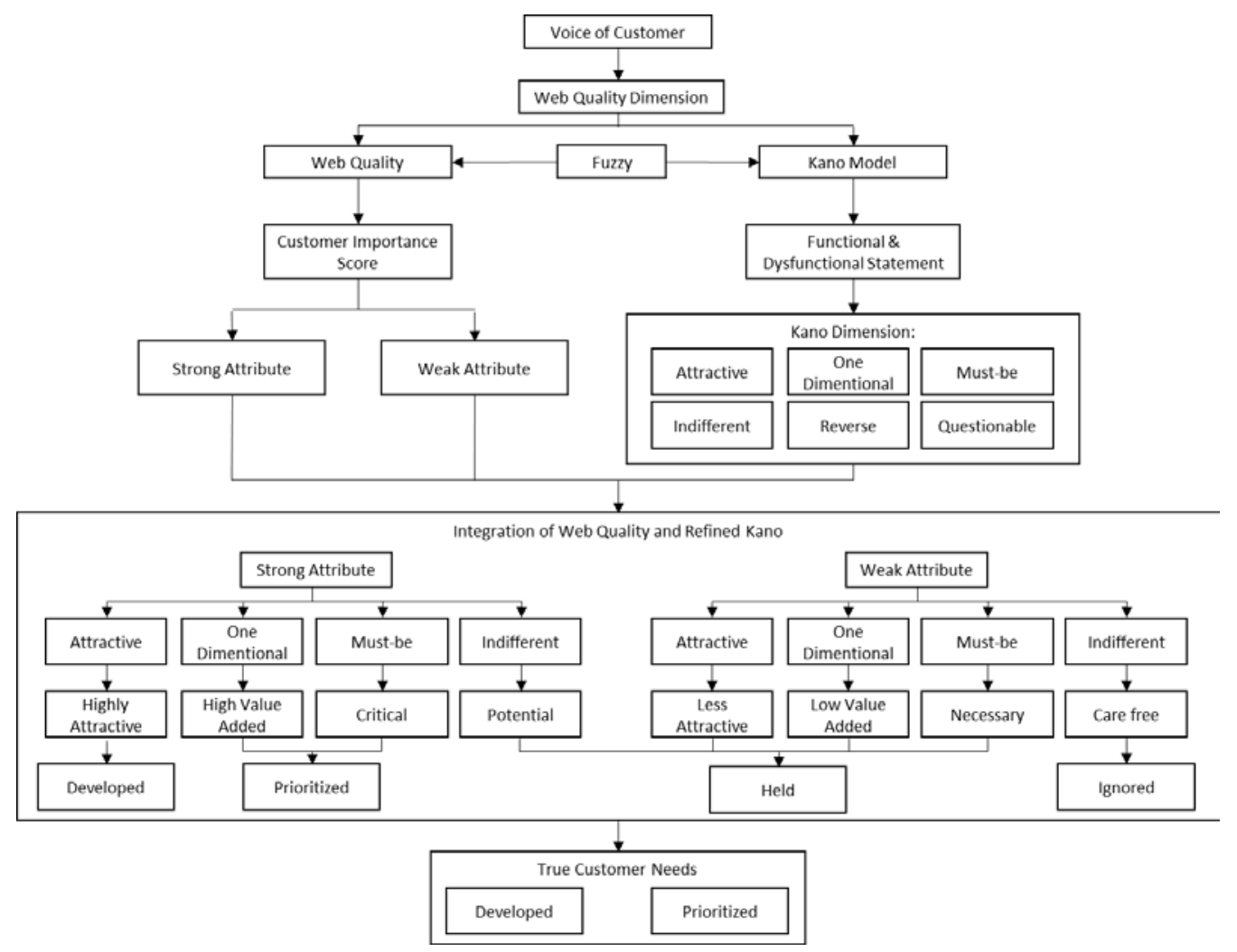

Figure 3. Conceptual Model.

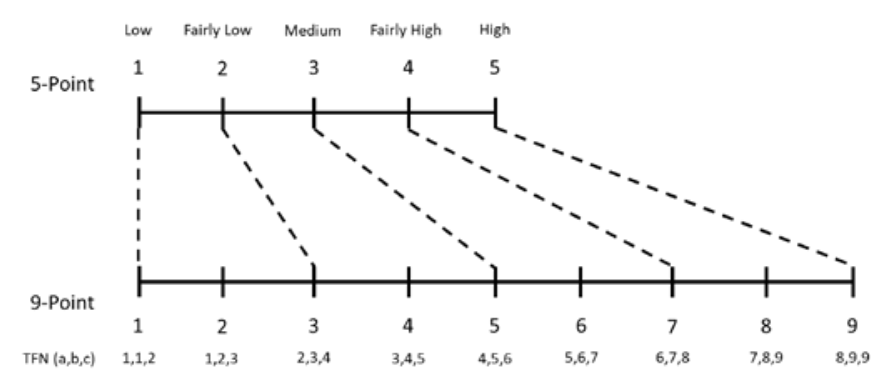

Figure 4. Conversion of 5-Scale to TFN-Scale

categories; attractive, must-be, one-dimensional, indifferent, reverse, and questionable.

Classification is done by categorizing the attributes by looking at the respondent's functional and dysfunctional answers. Then, do the encoding as shown in the image below.

After encoding the attribute from the respondent's answer, determining the category of each attribute can be using Blauth's Formula [5] as follows:

1. If (One-dimensional + Attractive + Must-be) $>$ (Indifferent + Reverse + Questionable), then the grade obtained is a maximum value of (One-dimensional, Attractive, and Mustbe).

2. If otherwise, then the grade obtained is a maximum value of (Indifferent, Reverse, and Questionable).

3. If it is same, then the grade obtained is a maximum value of (One-dimensional, Attractive, Must-be, Indifferent, Reverse, and Questionable).

\section{Review of fuzzy logic}

Fuzzy theory is a theory that uses mathematical models to present data that has uncertainty values, such as ambiguity, and obscurity in real life. This theory was first discovered by Professor L.A. Zadeh in 1965. The main objective of the fuzzy set theory is its ability to present obscurity. Fuzzy sets have characteristics that give each of the elements of a membership level ranging from zero or one [17]. This means that each element is not represented by a value of 0 or 1 , but can be between 0 and 1 so that it represents more uncertainty.

In traditional statistics, the opinion taken is the majority opinion in each element is represented by one feeling. But according to the fuzzy theory, a person's feelings cannot be represented by one feeling because each person has an unclear and different view. For example, someone's opinion regarding a website in traditional statistics can be "very like", but in fuzzy theory, it can be "very like, but a little dislike". That way, 
IPTEK Proceedings Series No. (1) (2020), ISSN (2354-6026)

International Conference on Business and Engineering Management 2020 (IConBEM 2020)

February $1^{\text {st }}$ 2020, Institut Teknologi Sepuluh Nopember, Surabaya, Indonesia

Table 2.

Data Fuzzyfication Process of QCH-1 Atribute

\begin{tabular}{|c|c|c|c|c|}
\hline \multirow{2}{*}{ Res. } & \multirow{2}{*}{$\begin{array}{c}\text { Likert } \\
\text { Answer }\end{array}$} & \multicolumn{3}{|c|}{ TFN } \\
\hline & & $\mathbf{a}$ & b & c \\
\hline 1 & 4 & 6 & 7 & 8 \\
\hline 2 & 4 & 6 & 7 & 8 \\
\hline 3 & 2 & 2 & 3 & 4 \\
\hline 114 & 5 & 8 & 9 & 9 \\
\hline 115 & 5 & 8 & 9 & 9 \\
\hline \multicolumn{2}{|c|}{ Average } & 6.88 & 7.87 & 8.36 \\
\hline
\end{tabular}

Table 3.

Defuzzyfication and Identification Atributes Category

\begin{tabular}{|c|c|c|c|c|c|c|}
\hline \multirow{2}{*}{ No } & \multirow{2}{*}{ Attribute } & \multicolumn{3}{|c|}{ TFN Limit Average } & \multirow{2}{*}{ CIV } & \multirow{2}{*}{ Attribute Category } \\
\hline & & $\mathbf{a}$ & b & c & & \\
\hline 1 & QCH-1 & 6.88 & 7.87 & 8.36 & 7.701 & Strong \\
\hline 2 & QCH-2 & 7.22 & 8.20 & 8.47 & 7.962 & Strong \\
\hline 3 & QCH-3 & 6.82 & 7.80 & 8.26 & 7.626 & Strong \\
\hline 21 & CSP-2 & 5,98 & 6,97 & 7,63 & 6,858 & Weak \\
\hline 22 & CSP-3 & 6.66 & 7.64 & 8.17 & 7.493 & Weak \\
\hline \multirow[t]{2}{*}{23} & CSP-4 & 6.68 & 7.66 & 8.15 & 7.496 & Weak \\
\hline & & rage & & & 7.560 & \\
\hline
\end{tabular}

Table 4.

Fuzzy-Kano Questionnaire

\begin{tabular}{cccccc}
\hline \hline & Like & Must-be & Neutral & Live-with & Dislike \\
\hline Functional & $25 \%$ & $25 \%$ & - & - & $50 \%$ \\
Dysfunctional & - & - & $50 \%$ & - & $50 \%$ \\
\hline \hline
\end{tabular}

Table 5.

QCH-1 Atribute Fuzzy-Kano Questionnaire Answers

\begin{tabular}{|c|c|c|c|c|c|c|c|c|c|c|}
\hline \multirow{2}{*}{ Res } & \multicolumn{5}{|c|}{ Functional } & \multicolumn{5}{|c|}{ Dysfunctional } \\
\hline & $\mathbf{a}$ & b & c & d & $\mathbf{e}$ & $\mathbf{a}$ & b & c & d & $\mathbf{e}$ \\
\hline 1 & $30 \%$ & $20 \%$ & $50 \%$ & $0 \%$ & $0 \%$ & $0 \%$ & $0 \%$ & $0 \%$ & $20 \%$ & $80 \%$ \\
\hline 2 & $80 \%$ & $20 \%$ & $0 \%$ & $0 \%$ & $0 \%$ & $0 \%$ & $0 \%$ & $0 \%$ & $0 \%$ & $100 \%$ \\
\hline 3 & $100 \%$ & $0 \%$ & $0 \%$ & $0 \%$ & $0 \%$ & $0 \%$ & $0 \%$ & $0 \%$ & $10 \%$ & $90 \%$ \\
\hline 114 & $100 \%$ & $0 \%$ & $0 \%$ & $0 \%$ & $\begin{array}{l}\ldots \\
0 \%\end{array}$ & $5 \%$ & $0 \%$ & $25 \%$ & $10 \%$ & $60 \%$ \\
\hline 115 & $80 \%$ & $20 \%$ & $0 \%$ & $0 \%$ & $0 \%$ & $0 \%$ & $0 \%$ & $0 \%$ & $30 \%$ & $70 \%$ \\
\hline $\begin{array}{l}\mathrm{a}=\text { Like } \\
\mathrm{b}=\text { Must-be } \\
\mathrm{c}=\text { Neutral }\end{array}$ & & & & & & $\begin{array}{l}=\mathrm{Liv} \\
=\mathrm{Dis}\end{array}$ & & & & \\
\hline
\end{tabular}

someone can provide more actual and objective data. Fuzzy can show someone who chooses "likes" more inclined to feel "really like", "likes enough" or even "dislikes".

\section{Integration of Fuzzy-Web Quality and Fuzzy-Refined Kano Conceptual Model}

The conceptual model below aims to determine the relationship between the variables used in this study. In the following figure, it is shown the integration between FuzzyWeb Quality and Fuzzy-Refined Kano Model, so it can dig deeper the attributes of the needs of prospective website users and gets True Customer Needs (TCN). To determine Web Quality dimension that the researcher used for further research, it is started by looking voice of customer (VoC) first. VoC helps us to design Web Quality and Kano Model questionnaire.

\section{E. Integration and Case Example}

\section{1) Integration of Fuzzy-Web Quality}

To determine Customer Importance Value (CIV), a questionnaire distribution required based on the dimension of
Web Quality that has been previously identified. Questionnaire of importance used the scale of linguistic variables that are easy to understand by respondents, namely "very important", "important", "important enough", "not important", and "very unimportant" [18]. The fuzzy integration into Web Quality is used to change the subjectivity value of the questionnaire to be

more objective by using the Triangular Fuzzy Number (TFN). The 5 scale conversion to TFN scale from previous research can be seen in the following image.

TFN represents a fuzzy characteristic interest expressed by respondents. It is of course to avoid subjective perception, vague and uncertain perception [18]. The values a, b, c are the lower limit value, the middle value, and the upper limit of the TFN. These values are averaged according to the type of boundary on each attribute, then done defuzzification to get the value of the Customer Importance Value (CIV) single of each attribute.

The defuzzification method has many types that can be used. This research adopts the most frequently used methods in 
IPTEK Proceedings Series No. (1) (2020), ISSN (2354-6026)

International Conference on Business and Engineering Management 2020 (IConBEM 2020)

February $1^{\text {st }} 2020$, Institut Teknologi Sepuluh Nopember, Surabaya, Indonesia

similar research, that is the center of gravity method. Equation

(1) is the calculation formula of the center of gravity method.

$$
N K P_{i}=\frac{\left[\left(c_{i}-a_{i}\right)+\left(b_{i}-a_{i}\right)\right]}{3}+a_{i}, \forall i
$$

Identifying strong and weak attributes can be seen from CIV attribute. The attribute that has CIV is greater than CIV average of the entire attribute, then it can be categorized as a strong attribute. While, the smaller CIV is categorized as a weak attribute. The fuzzification process, defuzzification, and the results of identification of strong attribute and weak attribute of this sample case research can be seen in the following table.

\section{2) Integration of Fuzzy-Kano}

Processing a Kano questionnaire used a single answer from the respondent judged incapable to reflect the perception of a complex respondent. The Fuzzy-Kano questionnaire can be used to understand the perception of respondents. This type of questionnaire allows respondents to personalize the answer according to perceived feelings [17]. Respondents to the FuzzyKano questionnaire can fill with multiple answers on each question by giving a percentage weight on each option. The sum of the percentage weights on each question equals $100 \%$. The following table is an example of a Fuzzy-Kano questionnaire implementation. The data encoding attribute of the Fuzzy-Kano questionnaire can use Fuzzy-Kano's Mode (FKM) with discrete definitions as follows [17].

Let $U$ and $V$ become the universal set of functional and dysfunctional questions, $P=\{P 1, P 2, \ldots, P p\}$ and $N=\{N 1$, $N 2, \ldots, N n\}$ with a set of linguistic variables $p$ and $n$ respectively in $U$ and $V$, which together build $p \times n$ in the Kano Model evaluation table, and $\left\{\mathrm{FS}_{k}, k=1,2, \ldots, r\right\}$ becomes a random sequence of fuzzy samples on $U$ and $V$.

On each $\mathrm{FS}_{k}$ sample, set the linguistic variables $P_{i}$ dan $N_{j}$ the normalized membership $m(P)_{k i}\left(\sum_{i=1}^{p} m(P)_{k i}=1\right)$ dan $m(N)_{k j}$ $\left(\sum_{j=1}^{n} m(N)_{k j}=1\right)$. Score $S_{i j}=\sum_{k=1}^{r} m(P)_{k i} \otimes m(N)_{k j}$ and $T_{h}$ (total attribute level) is the sum of the $S_{i j}$ with cells $(i, j)$ belongin to $h$ (quality attribute) in the evaluation table.

Then, the maximum value of $\left\{T_{h}\right\} \alpha$ is then referred to as the FKM of the associated quality attribute and the $\alpha$-cut is a significant classification level. If there are two attributes of a classified quality, then the dataset is called multi-fuzzy mode. In this study, the $\alpha$-cut limit used was 0.4 because the $\alpha$ value is a common boundary value often used in fuzzy-Kano calculations and can identify more details of Kano's category each respondent [17]. Therefore, the quality attributes of Kano that have a FKM value greater than or equal to 0.4 can represent the answers of the related respondents.

The following is an example of a Fuzzy-Refined Kano process based on discrete definitions above.

From the table above, the sample was used in the case of this research of 115 respondents to the fuzzy sample $F S=\{1.2, \ldots$, $115\}$.

With the value of $P$ and $N$ as a functional and dysfunctional answer of each respondent as can be seen in the following table.

Then normalization is done with the total value $P$ (Functional) and the value $N$ (dysfunctional) of each respondent's answer equals 1 . The following is the answer to the questionnaire attribute QCH-1 respondent 1 that has been normalized.

$$
\begin{aligned}
& m(P)=\{0.3,0.2,0.5,0,0\} \\
& m(N)=\{0,0,0,0,0.2,0.8\}
\end{aligned}
$$

Then, matrix multiplication is performed $m(P) \otimes m(N)$ which results in combination value $S$ according to the table $5 \times 5$ Kano evaluation.

$$
S=\left[\begin{array}{lllll}
0.00 & 0.00 & 0.00 & 0.60 & 0.24 \\
0.00 & 0.00 & 0.00 & 0.40 & 0.16 \\
0.00 & 0.00 & 0.00 & 0.10 & 0.40 \\
0.00 & 0.00 & 0.00 & 0.00 & 0.00 \\
0.00 & 0.00 & 0.00 & 0.00 & 0.00
\end{array}\right]
$$

Performed calculation of the total attribute level $\left(T_{h}\right)$ with summing the cell values found on the $S$ matrix based on the Kano Model attribute found in Table 2.

$$
T=\left\{\frac{M}{0.56}, \frac{O}{0.24}, \frac{A}{0.06}, \frac{I}{0.14}, \frac{R}{0}, \frac{Q}{0}\right\}
$$

To identify the category of Kano on each of the respondents answers, given a minimum $\alpha$-cut limit of 0.4 on the $T_{h}$ value. The Total attribute level that has the value more than 0.4 is represented by the number 1 , while the one with the value below 0.4 is represented by the number 0 .

Here are the results of the processing of Kano to 23 attributes of all the respondents answer using the Blauth's Formula.

3) Integration of Fuzzy Web-Quality and Refined Kano

After the data processing of Web Quality and Fuzzy-Kano questionnaires, it is necessary to integrate the second data of the questionnaire to find True Customer Needs (TCN). TCN can assist companies in determining appropriate measures for the improvement of the company's sales website services. The integration of these two processing will identify the attributes that need to be developed, prioritized existing, held, and ignored. The attribute that becomes TCN is an identified attribute developed and prioritized there.

The Fuzzy-Web Quality and Fuzzy-Kano integration resulted in the Refined Kano category which became the defining reference for TNC. Attributes that have a highly attractive category need to be developed; High value added and critical are prioritized; Potential, less attractive, low value added, and necessary events are held; and the free care category is ignored.

Examples of the result of the integration of Fuzzy-Web Quality and Fuzzy-Refined Kano cases of this research have 13 attributes categorized as high value added and 10 attributes categorized as low value added. It means, there are 13 attributes is prioritized to develop first. Result of integration of Fuzzy- 
IPTEK Proceedings Series No. (1) (2020), ISSN (2354-6026)

International Conference on Business and Engineering Management 2020 (IConBEM 2020)

122

February $1^{\text {st }}$ 2020, Institut Teknologi Sepuluh Nopember, Surabaya, Indonesia

Table 6.

QCH-1 Atribute Classification

\begin{tabular}{ccccccc}
\hline \hline Res & $\mathbf{M}$ & $\mathbf{O}$ & $\mathbf{A}$ & $\mathbf{I}$ & $\mathbf{R}$ & $\mathbf{Q}$ \\
\hline 1 & 1 & 0 & 0 & 0 & 0 & 0 \\
2 & 0 & 1 & 0 & 0 & 0 & 0 \\
3 & 0 & 1 & & 0 & 0 & 0 \\
114 & 0 & 1 & & 0 & 0 & 0 \\
115 & 0 & 1 & 0 & 0 & 0 & 0 \\
Frequency & 36 & 65 & 14 & 3 & 4 \\
\hline \hline
\end{tabular}

Table 7.

Kano Categorization Result

\begin{tabular}{|c|c|c|c|c|c|c|c|c|c|}
\hline \multirow{2}{*}{ Attribute Code } & \multicolumn{6}{|c|}{ Total Attribute Clasification } & \multirow{2}{*}{$\begin{array}{c}\mathbf{M}+\mathbf{O} \\
+\mathbf{A}\end{array}$} & \multirow{2}{*}{$\begin{array}{c}\mathbf{I}+\mathbf{R} \\
+\mathbf{Q}\end{array}$} & \multirow{2}{*}{ Kano Category } \\
\hline & $\mathbf{M}$ & $\mathbf{O}$ & A & I & $\mathbf{R}$ & $\mathbf{Q}$ & & & \\
\hline QCH-1 & 36 & 65 & 14 & 3 & 4 & 8 & 115 & 15 & $\mathrm{O}$ \\
\hline QCH-2 & 37 & 74 & 6 & 2 & 4 & 5 & 117 & 11 & $\mathrm{O}$ \\
\hline \multirow[t]{2}{*}{ QCH-3 } & 28 & 57 & 16 & 10 & 1 & 5 & 101 & 16 & $\mathrm{O}$ \\
\hline & & & & & $\cdots$ & & & & \\
\hline CSP-2 & 18 & 55 & 22 & 12 & 5 & 4 & 95 & 21 & $\mathrm{O}$ \\
\hline CSP-3 & 20 & 64 & 14 & 8 & 4 & 4 & 98 & 16 & $\mathrm{O}$ \\
\hline CSP-4 & 23 & 61 & 14 & 8 & 3 & 7 & 98 & 18 & $\mathrm{O}$ \\
\hline
\end{tabular}

Table 8.

Integration Fuzzy-Web Quality and Fuzzy-Refined Kano

\begin{tabular}{|c|c|c|c|c|}
\hline Attribute & Attribute Category & Kano Category & $\begin{array}{c}\text { Refined Kano } \\
\text { Category }\end{array}$ & Integration Result \\
\hline QCH-1 & Strong & $\mathrm{O}$ & High Value Added & Prioritized \\
\hline QCH-2 & Strong & $\mathrm{O}$ & High Value Added & Prioritized \\
\hline QCH-3 & Strong & $\mathrm{O}$ & High Value Added & Prioritized \\
\hline CSP-2 & Weak & $\mathrm{O}$ & Low Value Added & Held \\
\hline CSP-3 & Weak & $\mathrm{O}$ & Low Value Added & Held \\
\hline CSP-4 & Weak & $\mathrm{O}$ & Low Value Added & Held \\
\hline
\end{tabular}

Web Quality and Fuzzy-Refined Kano of this case example can be seen in the following table.

4) True Customer Needs

True Customer Needs (TCN) is an attribute that is then used for drafting recommendations to the company as a result of the integration of Fuzzy-Web Quality and Fuzzy-Refined Kano. Attributes that become TCN are attributes that belong to the Highly Attractive and High Value Added categories because these attributes that will greatly affect the potential user's satisfaction rate against the company's sales website services.

\section{CONCLUSION}

Web Quality and Refined Kano method itself has been often experienced developments, even the integration of the two methods are often done. However, the combination of fuzzy logic into the processing of both methods is still rare to find. The third combination of this method allows entrepreneurs to be more realistic in making decisions according to the actual needs that are directly from the target consumers. This allows it to happen because the fuzzy allows researchers to get the data according to the wishes of the user without having to be boxedmapped in one particular feeling.

The fuzzy use of the Web Quality and Refined Kano methods has a difference. In Web Quality, the fuzzification is done at the single answer conversion of scale- 5 to be the Triangular Fuzzy Number (TFN) chosen according to the level of efficacy needed in the study.A range of 1 to 9 can separate feelings at scale- 5 more clearly. Meanwhile, the fuzzification process of Refined Kano Model has been done since the filling questionnaire by prospective consumers.

Integration of fuzzy, Web Quality, and Refined Kano can produce more accurate and objective results than if the Web Quality and Refined Kano methods stand alone or in combination. The response of potential consumers is more complete and in reality, and can find the most appropriate recommendation and first priority to do in improving the company's sales website services. 
IPTEK Proceedings Series No. (1) (2020), ISSN (2354-6026)

International Conference on Business and Engineering Management 2020 (IConBEM 2020)

February $1^{\text {st }} 2020$, Institut Teknologi Sepuluh Nopember, Surabaya, Indonesia

\section{REFERENCES}

[1] Badan Ekonomi Kreatif, Opus, Jakarta: Bekraf RI, 2019.

[2] Simple Group, ICINC For You : Fashion, Jakarta: Badan Ekonomi Kreatif Republik Indonesia, 2019.

[3] C. Katawetawaraks dan C. L. Wang, "Online Shopper Behavior: Influences of Online Shopping Decision," Asian Journal of Business Research, 1(2), 2011.

[4] R. Anusha, "A Study of Web Quality Models," International Journal of Scientific and Research Publications, vol. 4, no. 12, 2014.

[5] C. Berger, R. Blauth, D. Boger, C. Bolster, G. Burchill, W. DuMouchel, F. Pouliot, R. Richter, A. Rubinoff, A. Shen, M. Timko dan D. Walden, "Kano's methods for understanding customer-defined quality," Center of Quality Management Journal, Fall, pp. 3-35, 1993.

[6] C. Calero, J. Ruiz dan M. Piattini, "Classifying Web Metrics Using the Web Quality Model,” Online Information Review, pp. 227-248, 2005.

[7] H. William, E. Delone dan McLean, "Model of Information Systems Success, A Ten-Year Update,” Journal of Management Information Systems, pp. 9-30, 2003.

[8] M. Moraga, C. Calero dan M. Piattini, "A First Proposal of a Portal Quality Model,” IADIS International Conference, pp. 630-638, 2004.

[9] D. Sampson dan N. Manouselis, "Web Portals- the New Gateways on Internet Information and Services.," A Flexible Evaluation Framework for Web Portals Based on Multi-Criteria Analysis, 2004.

[10] B. K. Hiremath dan A. Y. Kenchakkanavar, "An Alteration of the Web 1.0, Web 2.0 and Web 3.0 : A Comparative Study," Imperial Journal of Interdisciplinary Research (IJIR), 2(4), pp. 705-710, 2016.

[11] H. Joo, "A Study on Understanding of UI and UX, and Understanding of Design According to User Interface Change," International Journal of Applied Engineering Research, 12(20), pp. 9931-9935, 2017.

[12] K. Schulze dan H. Krömker, "A framework to measure user experience of interactive online products," Proc. the 7th International Conference on Methods and Techniques in Behavioral Research, p. 14, 2010.

[13] E. L. Law, V. Roto dan M. Hassenzahl, "Understanding, scoping and defining user experience: A survey approach,” Proc. the SIGCHI Conference on Human Factors in Computing Systems, pp. 719-728, 2009.

[14] M. Zarour dan M. Alharbi, "User Experience Aspects and Dimensions: Systematic Literature Review," International Journal of Knowledge Engineering, 3(2), 2017.

[15] N. Kano, N. Seraku, F. Takahashi dan S. Tsuji, "Attractive quality and must-be quality," Hinshitsu: The Journal of the Japanese Society For Quality Control, pp. 39-48, 1984.

[16] C.-C. Yang, "The refined Kano's model and its application,” Total Quality Management \& Business Excellence, 16 (10), pp. 1127-1137, 2005.

[17] Y.-C. Lee dan S.-Y. Huang, “A new fuzzy concept approach for Kano’s model,” Expert Systems with Applications, p. 4479-4484, 2009.

[18] P.-L. Hsieh, T.-M. Yeh dan J.-E. Chen, “Integrating Fuzzy SERVQUAL into Refined Kano Model to Determine the Critical Service Quality Attributes of Chain Restaurants," Review of Integrative Business and Economics Research, 4(4), pp. 142-157, 2015.

[19] E. A. Nawar, S. H. Backar, M. A dan El-Dardiry, "Integration of Blitz Quality Function Deployment and Fuzzy Analytical Hierarchy Process in Product Development," Proceedings of 85th ISERD International Conference, 2017. 